\title{
Homeostatic control of conjunctival mucosal goblet cells by NKT-derived IL-13
}

\author{
CS De Paiva ${ }^{1}$, JK Raince ${ }^{1}$, AJ McClellan ${ }^{1}$, KP Shanmugam $^{1}$, SB Pangelinan ${ }^{1}$, EA Volpe ${ }^{1}$, RM Corrales $^{1}$, \\ WJ Farley ${ }^{1}$, DB Corry ${ }^{2}$, D-Q Li ${ }^{1}$ and SC Pflugfelder ${ }^{1}$
}

Although the effects of the interleukin 13 (IL-13) on goblet cell (GC) hyperplasia have been studied in the gut and respiratory tracts, its effect on regulating conjunctival GC has not been explored. The purpose of this study was to determine the major IL-13-producing cell type and the role of IL-13 in GC homeostasis in normal murine conjunctiva. Using isolating techniques, we identified natural killer (NK)/natural killer T (NKT) cells as the main producers of IL-13. We also observed that IL-13 knockout (KO) and signal transducer and activator of transcription 6 knockout (STAT6KO) mice had a lower number of periodic acid Schiff (PAS) + GCs. We observed that desiccating stress (DS) decreases NK population, GCs, and IL-13, whereas it increases interferon- $\gamma$ (IFN- $\gamma$ ) mRNA in conjunctiva. Cyclosporine A treatment during DS maintained the number of NK/NKT cells in the conjunctiva, increased IL-13 mRNA in NK+ cells, and decreased IFN- $\gamma$ and IL-17A mRNA transcripts in NK + and NK - populations. C57BL/6 mice chronically depleted of NK/NKT cells, as well as NKT cell-deficient RAG1KO and CD1dKO mice, had fewer filled GCs than their wild-type counterparts. NK depletion in CD1dKO mice had no further effect on the number of PAS + cells. Taken together, these findings indicate that NKT cells are major sources of IL-13 in the conjunctival mucosa that regulates GC homeostasis.

\section{INTRODUCTION}

The conjunctiva covers the greatest proportion of the ocular surface area. It functions to maintain comfort and to support and protect the cornea through its tear-producing and mucosal immune functions. Goblet cells (GCs) are simple columnar secretory epithelial cells that secrete gel-forming mucins, such as MUC5AC, onto the ocular surface to form the mucous component of the tear film. The protein cores of mucins are synthesized in the rough endoplasmic reticulum and then transported to the Golgi apparatus. To date, over 15 types of mucin protein cores, known as MUCs, have been cloned. Soluble mucins that are secreted by the GCs have an integral role in stabilizing the precorneal tear layer. Decreased mucin production by the conjunctival GCs is well recognized to lead to sight-threatening corneal complications. GC loss is often observed in several blinding ocular surface diseases, including Sjögren's syndrome, StevensJohnson syndrome, ocular mucous membrane pemphigoid, and graft-vs.-host disease, ${ }^{1,2}$ where lack of a stable tear film may lead to corneal ulceration and perforation. The number of GCs varies among various mucosal tissues in the body. GCs are normally found in the conjunctiva, but scarcely found in the lung and in the villous epithelium of the small intestine, where they are upregulated with disease processes, such as asthma. ${ }^{3-7}$

Similar to other mucosal tissues, the conjunctiva is covered with epithelium containing dendritic antigen-presenting cells (APCs) and a variety of intraepithelial lymphocyte (IEL) populations. These immune cells belong to the conjunctiva-associated lymphoid tissue, a component of the mucosal immune system. ${ }^{8-12}$ IEL subsets in the conjunctiva that have been identified to date include $\mathrm{CD} 4^{+}, \mathrm{CD}^{+}$, and $\gamma \delta^{+} \mathrm{T}$ cells and natural killer $(\mathrm{NK})^{+}$cells. $^{13}$

NK cells are a type of cytotoxic lymphocytes that lack expression of the antigen receptors expressed by $\mathrm{B}$ and $\mathrm{T}$ cells ( $\mathrm{T}$-cell receptor (TCR)). They were first described for their ability to recognize and kill malignant cells. However, NK cells, along with other types of lymphocytes, are an important source of inflammatory cytokines, notably after encountering pathogens (viruses, bacteria, and protozoans). Natural killer T (NKT) cells are a minor subset of T lymphocytes that share cell-surface markers with conventional NK and T cells. They are identified by expression of TCR in addition to NK markers. NKT cells have been recently implicated in mucosal immunity and in a variety of inflammatory/autoimmune

${ }^{1}$ Ocular Surface Center, Department of Ophthalmology, Cullen Eye Institute, Baylor College of Medicine, Houston, Texas, USA. ${ }^{2}$ Department of Medicine, Baylor College of Medicine, Houston, Texas, USA. Correspondence: CS De Paiva (cintiadp@bcm.tmc.edu)

Received 23 March 2010; accepted 23 November 2010; published online 22 December 2010. doi:10.1038/mi.2010.82 
diseases, such as experimental murine and human ulcerative colitis, asthma, multiple sclerosis, and skin diseases (atopic dermatitis, psoriasis $)^{14-16}$ (see review in ref. 17).

NK and NKT cells are able to produce a myriad of cytokines, including interferon- $\gamma($ IFN- $\gamma$ ) and interleukin 13 (IL-13). IL-4 and IL-13, released by Thelper (Th)-2 lymphocytes, have been reported to increase GC number and mucin expression in nonocular mucosa. ${ }^{18}$ The importance of IL-13 in GC hyperplasia is supported by studies showing that direct stimulation of primary lung epithelial cells by IL-13 causes an increase in the population of GCs. ${ }^{18,19}$ In murine models of allergic asthma, mice repeatedly exposed to allergens or IL-13 develop GC hyperplasia of the airway epithelium. ${ }^{3-5}$

Although the effects of the IL-13 on GCs hyperplasia have been extensively studied in the gastrointestinal and respiratory tracts, its effect on regulating the density of filled GCs in the conjunctiva has not been explored. The purpose of this study was twofold: first, to identify the cellular source of IL-13 on the ocular surface and second, to evaluate the role of IL-13 in promoting conjunctival GC homeostasis.

\section{RESULTS \\ NK (and NKT) cells are the major source of IL-13 in the ocular surface}

NK and NKT cells have been implicated as major sources of different cytokines, such as IFN- $\gamma$ and IL-13 in a variety of tissues. ${ }^{6,20-22}$ IELs (CD8 + and $\gamma \delta+$ ) from small intestine and lungs have also been reported to produce IL-13. ${ }^{23,24}$ Because $\gamma \delta+$ are capable of producing IL-13, we separated cell populations from the normal murine ocular surface using immunobeads, and performed enzyme-linked immunosorbent spot (ELISPOT) for IL-13 using the isolated cells. Splenocytes were used as positive controls.

$\gamma \delta \mathrm{T}$ cells were isolated from nonstressed ocular surface C57BL/6, using a multistep procedure, where B cells and $\mathrm{CD} 11 \mathrm{~b}+$ cells were initially depleted (using a dual cocktail that contained both B220 and CD11b antibodies) followed by positive selection of remaining $\gamma \delta$ T cells from the $\alpha \beta+\mathrm{T}$ cells. We observed that the majority of IL-13-producing cells were in the B220/CD11b + populations (Figure 1a).

Because NK cells can also express both CD11b and B220 surface markers (data not shown; see refs. 20, 21, and 25), the NK cell population was considered a good candidate to contain the IL-13-producing cells. NK cells can be identified by several markers, including NK1.1 and DX5 antibodies. The NK1.1 antibody identifies NK cells in selected mouse strains, such as C57BL, FVB/N, and NZB. ${ }^{20,21}$ The DX5 antibody targets the $\mathrm{CD} 49 \mathrm{~b}$ protein, ${ }^{26}$ an $\alpha$-integrin subunit that makes up half of the $\alpha 2 \beta 1$ integrin duplex. The CD49b protein is found in both NK and NKT cells of all mouse strains, including the NK1.1negative strains (129A, AKR, BALB/c, C3H/He, C57BR, C58, CBA, DBA/1, DBA/2, MRL/lpr, and SJL). Therefore, the DX5 antibody can be considered a pan-NK marker, because it has no strain restriction.

To test the hypothesis that NK cells could be the IL-13-producing cells, we then performed a positive NK isolation from splenocytes and from cells collected from the normal ocular surface, using the pan-NK antibody DX5. Two populations were isolated, NK-positive cells (NK- and NKT-enriched population) and NK-negative cells (non-NK cells, comprising T cells, epithelial cells, B cells, $\gamma \delta$ T cells, CD11b + cells, and so on). Isolated cell populations were subsequently subjected to ELISPOT for IL-13 or lysed for analyzing gene expression. Using this approach, we confirmed that the majority of IL-13-producing cells are located in the NK/NKT + population, in both spleen and ocular surface populations (Figure 1b). Our results agree with McDermott et al., ${ }^{6}$ who have shown that NK-derived IL-13 mediates the GC hyperplasia that characterizes infection with the helminth Trichinella spiralis. The small intestine is another organ of the body where GCs can be found in the normal state, although at lower numbers than the conjunctiva, as opposed to the lungs where there is a paucity of GCs (see Supplementary Figure S1 online).

Because of the paucity of cells isolated from the ocular surface, the efficiency of NK isolation was confirmed in splenocytes using flow cytometry and the NK1.1-specific antibody that reacts with the NK and NKT cells in the C57BL/6 mouse strain (Figure 1c). At the same time, we measured the percentage of NKT cells among the isolated NK/NKT-positive cells by performing a dual-color flow cytometry staining with NK1.1 and TCR $\alpha \beta$ antibodies. Figure 1d demonstrates that $\mathrm{NK}+$ cells exhibited a 30-fold enrichment in the expression of NK1.1 over the unfractionated spleen population (Figure 1c) and approximately half of the selected NK + cells expressed TCR $\alpha \beta$ (Figure 1e), therefore characterizing NKT + cells. We also confirmed higher expression of CD49b mRNA in the NK+ population when compared with the NK - cells using real-time PCR (data not shown). These results confirmed that the pan-NK microbead magnetic isolation method provides an excellent enrichment for both NK and NKT in the NK+ population.

During the isolation of cells from the ocular surface, epithelial cells are mixed with $\mathrm{T}$ cells. To address the possibility that epithelial cell contaminants in the NK/NKT + population could be producing IL-13, we performed a magnetic depletion of all bone marrow-derived cells from the pool of cells collected from the ocular surface in nonstressed C57BL/6 mice, using an antibody that targets CD45 (bone marrow-derived cell marker). Our results show that CD $45+$ cells produce twice as much IL-13 as CD45 - cells (Figure 1f).

After identifying the NK/NKT cell population as the IL-13 producers in normal murine conjunctiva, we evaluated the phenotype of the NK + and NK - cell populations (Figure 2). NK and NKT cells are capable of producing either IL-13 or IFN- $\gamma$ cytokines. Using splenocytes as calibrators, we observed that the ocular mucosal NK + and NK - cells exhibited significantly higher levels of IL-13, IL-17A, IL-17F, and IL-22 mRNA transcripts than normal, nonstimulated NK + splenocytes. On the other hand, IL-21 levels were significantly elevated in NK - cells from spleen, compared with the $\mathrm{NK}$ - cells from the ocular surface.

Nonstressed ocular surface NK + cells expressed significantly higher IL-13 and lower IL-17A and IL-22 mRNA than NKcells $(P<0.001$ for all of them). The levels of IL-21, IL-17F, and 

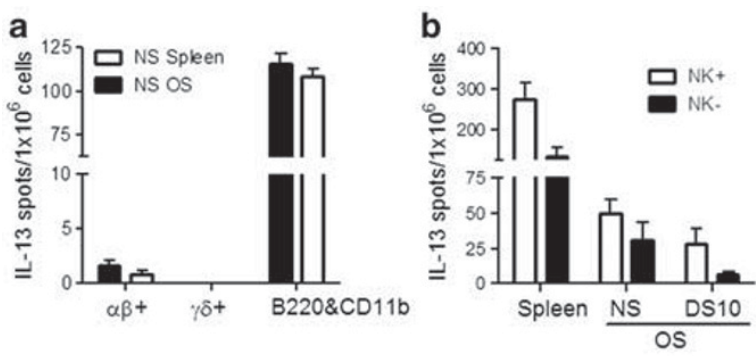

c

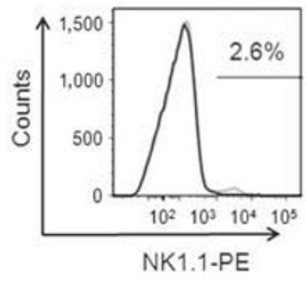

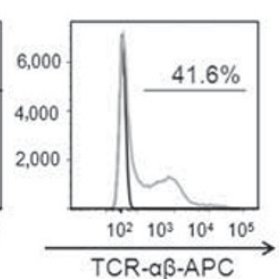

d

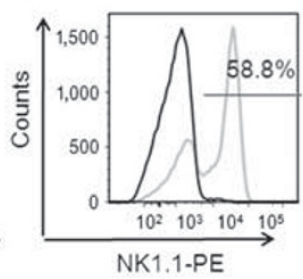

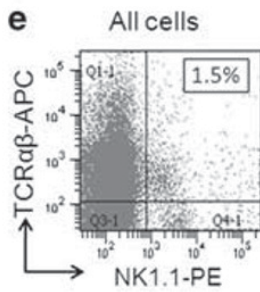
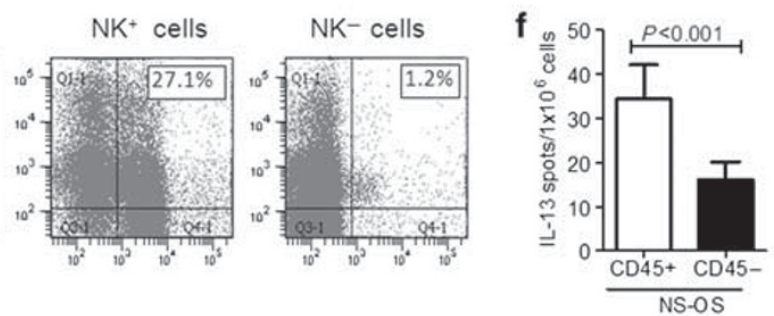

Figure 1 NK and NKT cells produce IL-13. (a) Mean \pm s.d. of interleukin 13 (IL-13) enzyme-linked immunosorbent spots (ELISPOTs) after $\gamma \delta+$ isolation from nonstressed (NS) ocular surface (OS) and NS spleen, showing the three isolated populations $(\alpha \beta+, \gamma \delta+$, and B220 and CD11b+ cells). (b) Mean $\pm S$. d. of IL-13 ELISPOTs after natural killer (NK) isolation from NS and desiccated-stressed (DS) OS for 10 days (DS10) and NS spleen, showing the two isolated populations, NK positive (+) and NK negative (-). (c) Histogram of flow cytometry analysis of total splenocytes stained with NK1.1-phycoerythrin (PE)-conjugated antibody (gray line) or T-cell receptor $\alpha \beta$-antigen-presenting cell (TCR $\alpha \beta-A P C$ ) and isotype control antibody (black line). The number over line indicates percentage of positive cells over the isotype control antibody. (d, e) Flow cytometry analysis. Lymphocytes were gated based on characteristic light-scatter properties, and single lymphocytes were gated based on forward scatter height vs. forward scatter area (FSC-A). The numbers in the quadrants or over line indicate the percentage of cells. (d) Histogram of flow cytometry analysis of NK-positive cells stained with NK1.1-PE-conjugated antibody (gray line) or isotype control antibody (black line). The number over line indicates percentage of positive cells over the isotype control antibody. (e) Flow cytometry analysis of freshly isolated NK cells dual stained with NK1.1-PE +TCR $\alpha \beta$ in all populations (all cells=no fraction, NK+, and NK - cells) from NS spleens. Percentage of double-positive cells is indicated in top right quadrant. (f) Mean \pm s.d. of IL-13 ELISPOTs after CD45 isolation from NS OS.

IL-4 mRNA transcripts were not different between ocular NK+ and NK - cells. These results suggest that conjunctival NK + cells are very unique when compared with NK cells in lymphoid tissues, such as the spleen. They also point out that NK+ cells produce a different profile of cytokines than the $\mathrm{NK}$ - cells.

\section{Effects of desiccating stress (DS) on NK population}

We then evaluated the effects of DS on the number of filled GCs and NK populations on the ocular surface. The DS is achieved by subjecting mice to a cholinergic blockade and by placing them in a low-humidity drafty environment chamber, as previously described. ${ }^{27-29}$ Cholinergic blockade of the lacrimal gland secretion is achieved by subjecting mice to subcutaneous injection of scopolamine q.i.d. (0800, 1200, 1400, and 1700 hours), for 5 or 10 consecutive days (DS5 or DS10, respectively). Mice were then placed in a cage with a perforated plastic screen on one side to allow airflow from a fan placed 6 inches in front of it for $16 \mathrm{~h} /$ day. Room humidity was maintained at 30-35\%. Control mice were maintained in a nonstressed environment containing $50-75 \%$ relative humidity without exposure to forced air.

Our DS model has been well documented to induce a dry-eye phenotype in mice, ${ }^{27-29}$ with features similar to humans, including corneal barrier disruption and a decrease in the number of periodic acid Schiff (PAS) filled conjunctival GCs. This model of dry-eye disease has been used previously with no discernible ill effects from the pharmacological inhibition of tear secretion with scopolamine. ${ }^{30}$ We also noted that treatment with scopolamine alone without DS was not sufficient to decrease the number of filled GCs. ${ }^{31}$
One of the features of this model is a progressive decrease in the number of filled PAS + GCs, which is most pronounced after 10 days of desiccation (DS10, Figure 3a). As MUC5AC is one of the mucins produced by GCs, we evaluated MUC5AC expression in whole conjunctiva of mice subjected to DS, at the transcription and protein levels. Although there was no change in the number of MUC5AC mRNA transcripts (Figure 3b), we observed a significant decrease in MUC5AC protein levels after 5 and 10 days of DS (Figure 3c).

Using flow cytometry analysis of total cells isolated and pooled from the ocular surface of five mice, we observed a significant decrease in the NK/NKT + lymphocyte population of mice subjected to DS for 5 or 10 days compared with nonstressed control mice (Figure 3d and e). This numerical decrease in NK/NKT + cells paralleled the decrease in filled GCs (Figure 3a).

Because DS for 5 and 10 days caused a numerical decrease in both filled GCs and NK/NKT cells, we evaluated gene expression in NK + and NK - cells at these time points (Figure 2). Our results demonstrated that $\mathrm{NK}+$ cells, after desiccation for 5 and 10 days, had significant lower levels of IL-13 transcripts than nonstressed NK + cells $(P<0.001$ for both days of treatment). There was also a significant decrease in IL-13 mRNA levels in the NK - population after DS. DS had no effect on mRNA levels of IL-4, another Th-2-related cytokine. These results indicate that there was an overall decrease in GC-supporting IL-13 in response to DS from both cell populations, but this decrease was more pronounced in the $\mathrm{NK}+$ cell population.

We have previously noted that DS induces an increase in IFN- $\gamma$ protein in tears and mRNA in conjunctiva of C57BL/ 6 mice, ${ }^{32}$ 

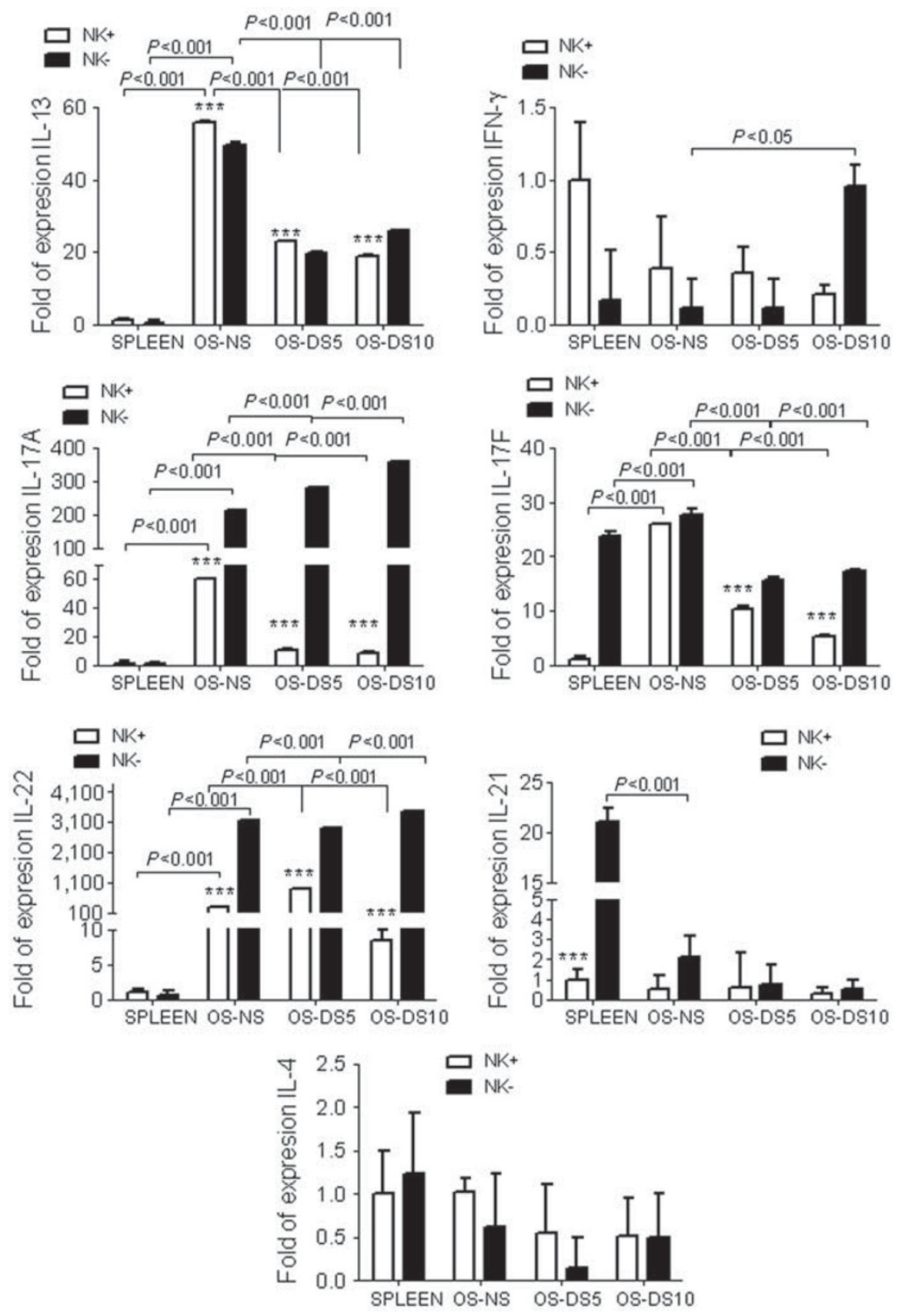

Figure 2 Gene expression analysis of isolated NK populations. Relative fold expression in natural killer (NK)/natural killer T (NKT)-positive and -negative populations. mRNA transcript levels of interleukin 13 (IL-13), interferon- $\gamma$ (IFN- $\gamma$ ), IL-17A, IL-17F, IL-22, IL-21, and IL-4 in freshly isolated NK positive (NK+) and negative (NK-) cells isolated cells from nonstressed (NS) and desiccating-stressed (DS) ocular surface (OS) for 5 (DS5) or 10 days (DS10) and normal spleen. ${ }^{* * *} P<0.001$, comparison of $\mathrm{NK}+\mathrm{vs}$. NK - populations within the tissue. Comparison of different NK populations across different time points is shown by numerical values in the graph.

findings that were confirmed in conjunctival cells of human patients with dry eye. ${ }^{33}$ We have also observed that there is a concomitant increase in IL-17A. ${ }^{33}$ To further investigate the effects of DS on NK cytokine profile, we studied the expression of Th- 1 and Th-17 cytokines, IFN- $\gamma$, IL-17A, IL-17F, and IL-22 in NK + and NK - cell populations (Figure 2). DS induced a significant decrease in IL-17A expression at both 5 and 10 days in NK + cells $(P<0.001$ for both). IL-22 expression in NK + cells significantly increased after 5 days of desiccation, but significantly decreased at the later time point. In contrast,
NK - cells had significantly higher levels of IFN- $\gamma$, IL-17A, and IL-22 mRNA transcripts compared with nonstressed NK - cells $(P<0.001)$. It is interesting to note that IL-17A peaked earlier ( 5 days) than IFN- $\gamma$ (10 days) in non-NK cells. IL-17F expression decreased in both populations with DS, with the greatest decrease in the NK+ population. There was no change in IL-21 mRNA transcript levels with DS in either population. These results indicate that although $\mathrm{NK}+$ cells are capable of producing IL-17A and IFN- $\gamma$, non-NK (NK-) cells, including CD4+ $\mathrm{T}$ cells, appear to be the main producers of these cytokines after 
a
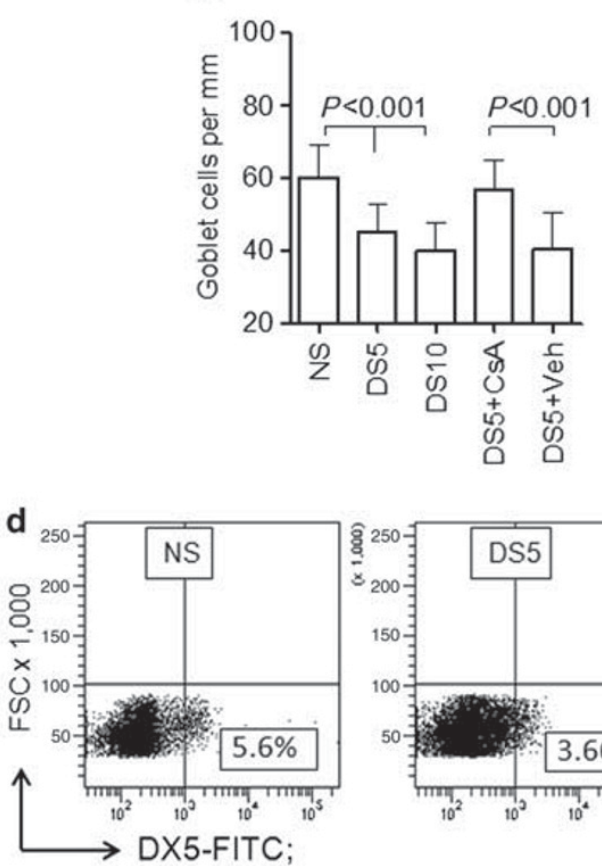

f
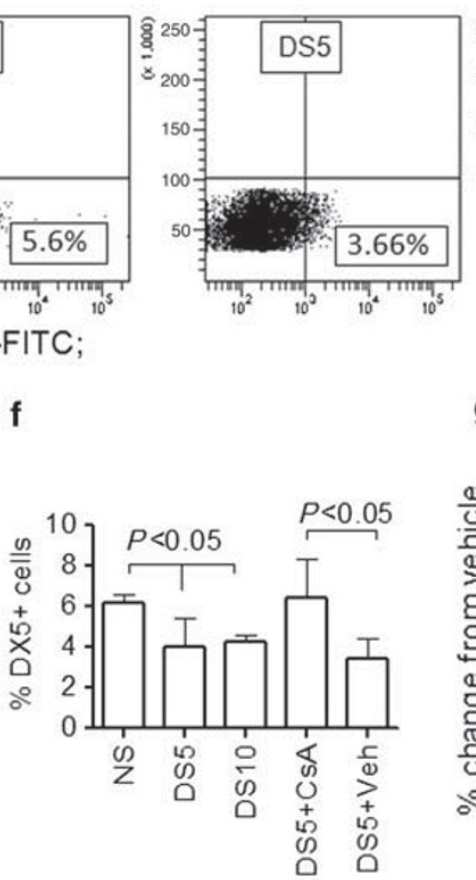

b

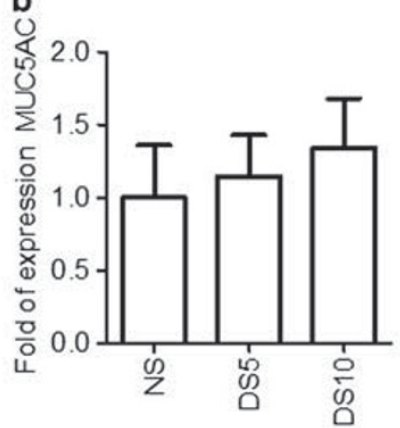

c

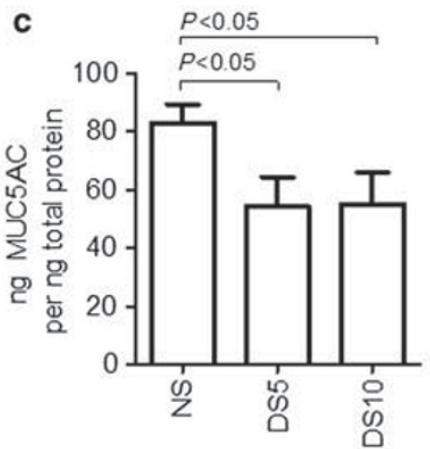

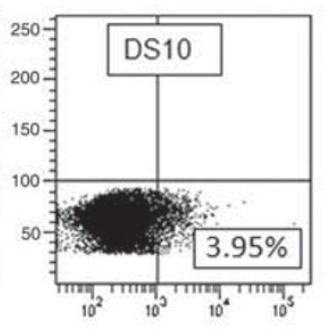
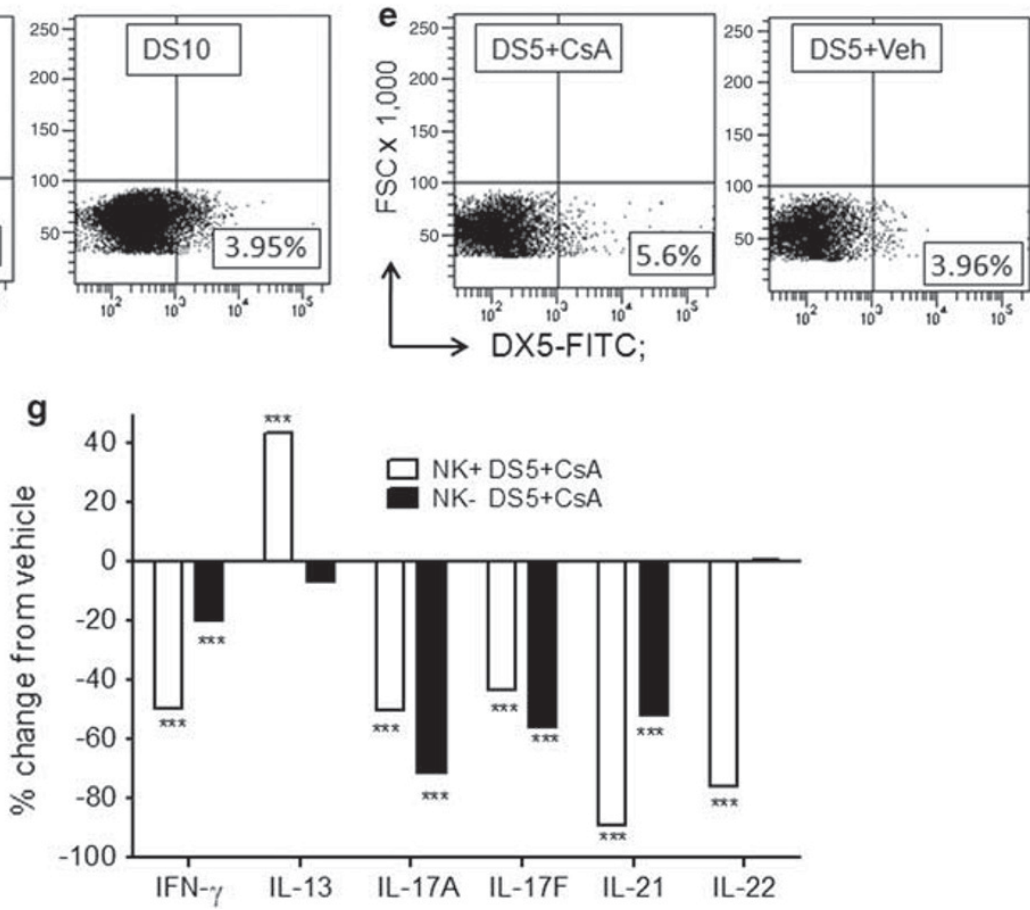

Figure 3 Effects of CsA treatment on NK and NKT cells. (a) Mean \pm s.d. of conjunctival goblet cell (GC) density in nonstressed (NS) C57BL/6 control mice and mice subjected to desiccating stress for 5 or 10 days (DS5 and DS10, respectively) or DS5 treated with Cyclosporine A (DS5+CsA) or DS5 treated with CsA vehicle (DS5+Veh). (b) mRNA transcript levels of MUC5AC in conjunctiva of NS C57BL/6 control mice and mice subjected to DS5 and DS10, respectively. (c) Mean \pm S.d. of protein concentrations of MUC5AC in conjunctiva of NS C57BL/6 control mice and mice subjected to DS5 and DS10, respectively. (d, e) Representative flow cytometry analysis of freshly isolated ocular surface cells stained with pan-NK marker DX5-fluorescein isothiocyanate (FITC)-conjugated antibody in NS C57BL/6 controls mice and mice subjected to DS5 and DS10, respectively (d) or DS5 treated with CsA (DS5+CsA) or DS5 treated with CsA vehicle (DS5+Veh) (e). Lymphocytes were gated based on characteristic light-scatter properties, and single lymphocytes were gated based on forward scatter height vs. forward scatter area (FSC-A). Numbers in the quadrants indicate the percentage of cells. (f) Mean \pm s.d. of the percentage of DX5 + cells evaluated by flow cytometry in three independent experiments. (g) Percentage change in the level of expression of interferon- $\gamma$ (IFN- $\gamma)$, IL-13, IL-17A, IL-21, and IL-22 mRNA transcripts in CsA-treated NK + and NK- cell populations, compared with vehicle. ${ }^{* \star *} \mathrm{P}<0.001$, comparison of $\mathrm{NK}+$ or $\mathrm{NK}-\mathrm{DS} 5+\mathrm{CSA}$ vs. the same population from DS5+ vehicle.

desiccation. In support of these findings, we previously observed that DS induces a significant CD $4+\mathrm{T}$-cell infiltration in the ocular surface. ${ }^{32,33}$

\section{Modulation of NK and GC populations by topical cyclosporine A (CsA) treatment}

CsA $0.01 \%$ emulsion is the only Food and Drug Administration (FDA)-approved drug to treat dry-eye disease. One striking consequence of CsA treatment on dry eye is a significant increase in conjunctival GC numbers. ${ }^{34}$ We have previously shown that IFN- $\gamma$ has a major role in inducing conjunctival metaplasia and decreasing the number of filled GCs, as IFN- $\gamma$ knockout (KO) mice were resistant to desiccating-induced phenotype changes. ${ }^{32}$

Because treatment with CsA for 5 days was sufficient to elicit a significant increase in the number of PAS + cells in our model (see refs. 35 and 36, and Figure 3a), we evaluated the effects on CsA treatment on the number and phenotype of NK cells at 5 days.

Using flow cytometry to measure NK cells obtained from the ocular surface of mice after DS and treatment with CsA or its vehicle, we observed that CsA topical treatment retains $\mathrm{NK}+$ 
cells in the ocular surface, and that this effect was significantly higher than its vehicle (Figure $\mathbf{3 c}$ and $\mathbf{d}$ ).

We then asked if CsA was capable of modulating the phenotype of NK + and NK - cells. To answer this question, we evaluated T-cell-related cytokines in isolated populations of $\mathrm{NK}+$ and $\mathrm{NK}$ - cells after treatment with either CsA or its vehicle. Figure 3e shows gene expression of $\mathrm{NK}+$ and $\mathrm{NK}$ - cells isolated using magnetic beads with the results presented as percentage change of CsA vs. vehicle. CsA treatment significantly increased the expression of IL-13 in NK + cells, whereas it decreased the expression of IFN- $\gamma$, IL-17A, IL-17F, and IL-21 in both NK + and NK - cell populations. It is worth noting that the greatest effect of CsA on IFN- $\gamma$ expression was on NK + cells, whereas for IL-17A the effect was greater in NK - cells.

These results show that CsA is capable of not just maintaining the normal density of NK/NKT + cells on the ocular surface, but also of maintaining the cytokine phenotype of these cells in a nonstressed state. It is worth noting that CsA treatment modulated the expression of cytokines, such as IL-17A, in nonNK cells.

\section{IL-13 promotes GC differentiation in the conjunctiva}

We then proceeded to evaluate the role of IL-13 on conjunctival GC homeostasis. IL-13 operates through a receptor that is a heterodimer of IL-4 receptor $\alpha$ (IL-4R $\alpha$ ) and IL-13R $\alpha 1$, with IL-4 and IL-13 both using IL-4R $\alpha$ chain for signal transduction. ${ }^{18}$ Both of IL-4 and IL-13 cytokines use Janus kinases to initiate signaling and activate signal transducer and activator of transcription-6 (STAT6), which is a transcription factor required for many of their biological functions. ${ }^{37}$ STAT6 is also a transcription factor regulating expression of IL-13 and IL-4, and lack of STAT6 results in blockade of Th-2 development. ${ }^{38}$ STAT6 - / mice fail to generate IgE and a Th-2 cytokine response and consequently they fail to develop airway inflammation, airway hyperresponsiveness, or GC hyperplasia during soluble ovalbumin-induced allergic airway disease. ${ }^{39,40}$

First, we investigated the presence of IL-13 and IL-13R $\alpha 1$ in the conjunctiva of nonstressed C57BL/6. Immunostaining for IL-13 was localized to the basal conjunctival epithelium primarily in the area where GCs are located and to some cells present in the stroma (Figure 4a). IL-13R $\alpha 1$ immunoreactivity was present in the conjunctival epithelium, with very rare cells in the underlying stroma (Figure $\mathbf{4 b}$ ). The secondary antibody alone control reaction yielded no color development (Figure 4c). The ELISPOT experiments in Figure 1f indicate that epithelial cells are not the major producers of IL-13. It is possible that the immunostaining may detect IL-13 bound to IL-13R $\alpha 1$ positive epithelial cells rather than to IL-13 produced by these cells. Alternatively, it could be binding to mucin in the GCs. The effects of DS on IL-13R expression will be described in a separate manuscript (De Paiva et al., in preparation).

We then evaluated gene expression in whole conjunctiva. Levels of IL-13 mRNA in the conjunctiva decreased with DS, whereas there was an increase in IFN- $\gamma$ mRNA transcripts (Figure 4d), resulting in a marked fivefold decrease in IL-13/IFN- $\gamma$ ratio (Figure 4e). This may indicate that the balance of IL-13 and IFN- $\gamma$, rather than the concentrations of either cytokine alone, may reflect the type of T-helper response after DS.

Next, we evaluated the direct effects of IL-13 on the number of filled conjunctival GCs using several approaches. The first was to evaluate if daily exogenous administration of IL-13 during DS would prevent the decrease in GC numbers. As noted in Figure 4 f, daily subconjunctival injections of IL- 13 for 4 days concomitant with DS significantly increased filled GC numbers compared with vehicle control.

Our subsequent step was to evaluate GCs in IL-13KO in nonstressed and stressed conditions. In previously reported studies, IL-13KO mice failed to induce GC hyperplasia in the intestine after nematode infection, in contrast to wild-type mice. ${ }^{6}$ Our IL-13KO mice have a C57BL/6 background and they were compared with this strain (Figure 4g). At baseline, IL-13KO mice had a significantly lower number of filled GCs than their wild-type counterparts, and after DS for 5 days, they exhibited a further significant $20 \%$ decrease in filled GCs.

We further investigated the role of IL-13 in supporting GCs by evaluating STAT6KO mice. Because STAT6KO mice have a $\mathrm{Balb} / \mathrm{c}$ background, they were compared with this strain. Balb/c mice are a Th-2-prone mouse strain, and we have previously found that they are resistant to acute, DS-induced corneal barrier disruption and reduction in the number of filled GCs after 5 days of DS. ${ }^{41}$ At baseline, nonstressed STAT6KO mice had a significantly lower number of filled GCs than nonstressed $\mathrm{Balb} / \mathrm{c}$, and it was in the same range observed in Balb/c mice subjected to DS for 10 days. DS for 5 days produced a further significant decrease in the number of filled GCs in the STAT6KO strain (Figure 4h).

Both IL-13 and STAT6KO mice manifest a reduced number of filled GCs at baseline, and after DS, there is a further decrease in the number of these cells. Although lower than the control, they still have some GCs. This indicates that other growth factors/ cytokines may also be involved in GC homeostasis.

Collectively, these results indicate that the normal murine conjunctiva has a Th- 2 tone that changes to a Th-1 in response to experimental DS. They also point to an essential role of IL-13 in regulating GC differentiation and homeostasis in the conjunctival mucosa.

\section{Effects of NK and NKT cell neutralization on conjunctival GC density}

To confirm that indeed NK-derived IL-13 supports GCs, we performed in vivo depletion of NK and NKT cells using systemic administration of the NK1.1 antibody. This antibody has been shown to both neutralize and deplete NK and NKT cells in a variety of systems and it is routinely used for these purposes. ${ }^{42-46}$

To create a mouse chronically depleted of NK and NKT cells, we performed weekly intraperitoneal injections of either NK1.1 antibody or the isotype control antibody in young C57BL/6 mice from 3 to 8 weeks of age (modified from a technique described by Koo et al. $\left.{ }^{46}\right)$. Mice received their first intraperitoneal injection at 21 days of age, as soon as they were weaned. At 8 weeks, a subset of NK1.1 antibody-treated mice was also subjected to DS 

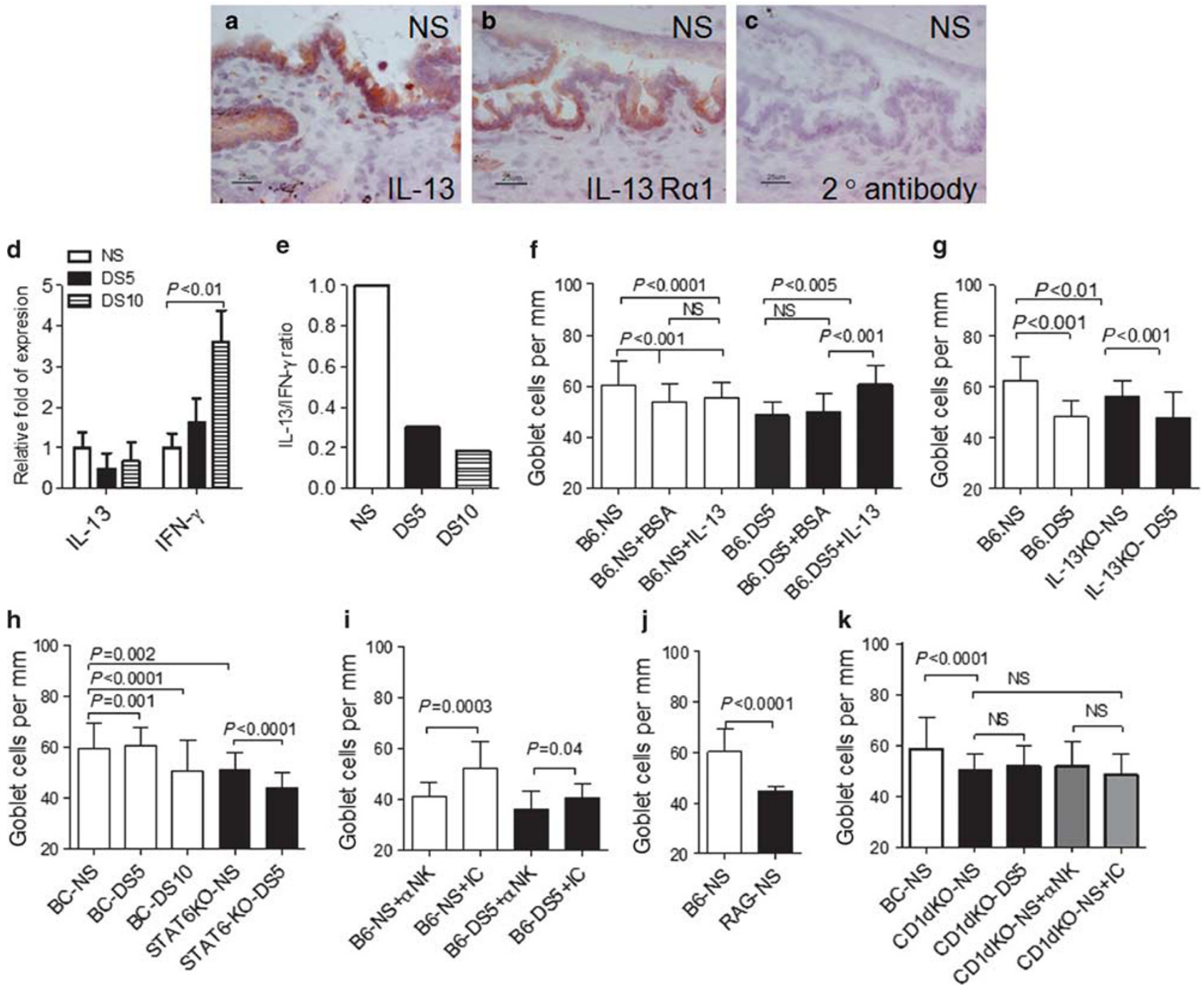

Figure 4 IL-13 expression and goblet cell analysis. (a-c) Immunohistochemical staining for interleukin 13 (IL-13; red, in a) and IL-13 receptor $\alpha 1$ (IL-13R $\alpha 1$; red, in b) and goat anti-rabbit secondary antibody alone (c) in conjunctiva sections of nonstressed (NS) control mice. Scale bar $=25 \mu \mathrm{m}$. (d) mRNA transcript levels of IL-13 and interferon- $\gamma$ (IFN- $\gamma$ ) in conjunctiva in NS control mice and mice subjected to desiccating stress for 5 or 10 days (DS5 and DS10, respectively). (e) Ratio of IL-13/IFN- $\gamma$ mRNA transcripts in conjunctiva. (f) Mean \pm s.d. of goblet cell (GC) density in NS C57BL/6 (B6) control mice and mice subjected to DS5 and mice after subconjunctival injection of BSA (+BSA) or IL-13 (+ IL13). (g) Mean \pm S.d. of GC density in NS C57BL/6 (B6) controls mice and mice subjected to DS5 and IL-13 knockout (KO) mice. (h) Mean \pm s.d. of GC density in NS Bal/c (BC) control mice and mice subjected to DS5 and DS10 and signal transducer and activator of transcription 6 knockout (STAT6KO) at baseline and after DS5. (i) Mean \pm S. d. of GC density in NS C57BL/6 mice (B6) that received systemic injection of neutralizing antibody (NK1.1) to natural killer (NK) cells ( $\alpha$ NK) or isotype control (IC) antibody before NS and after DS5. (j) Mean \pm s.d. of GC density in NS C57BL/6 (B6) control and RAG1KO mice. (k) Mean \pm s.d. of GC density in NS Bal/c (BC) control mice and CD1dKO at baseline, NS, and after DS5. A separate group NS CD1dKO mice received systemic injection of depleting antibody (NK1.1) to NK cells ( $\alpha$ NK) or IC antibody.

for 5 days and the results compared with isotype-treated mice. Both groups of mice received a total of six injections. Depletion of NK1.1 + cells was confirmed using flow cytometry at the end of the experiment (data not shown). Our results are summarized in Figure 4i. Depletion of NK and NKT cells significantly decreased the number of filled GCs in nonstressed mice and in mice subjected to DS for 5 days, compared with the isotype control group ( $P=0.0003$ and $P=0.04$, respectively). These results indicate that NK- and NKT-derived IL-13 is critical for the filling of GCs in normal and under stress situations.

To investigate the individual contributions of NK and NKT cells to the homeostatic control of conjunctival GCs, we then evaluated GC density in RAG1KO mice, which have normal NK cells, but lack NKT and T cells. Evaluation of GCs in nonstressed RAG1KO mice demonstrated that they have a significantly lower number of filled GCs compared with control C57BL/6 mice (Figure 4j). RAG1KO mice lack T cells, and therefore, we did not evaluate these mice under DS. We have previously shown that $\mathrm{CD} 4+\mathrm{T}$ cells have an important role in the pathogenesis of the disease. ${ }^{27}$

Using a similar approach, we evaluated the density of filled GCs in a NKT cell-deficient strain (CD1dKO mice in a Balb/c background). CD1dKO mice showed a decreased number of filled GCs in their nonstressed baseline when compared with 
wild-type control mice, but no change was noted after DS for 5 days (Figure 4k). Furthermore, chronic depletion of NK cells in the NKT-deficient CD1dKO strain did not change the number of PAS + GCs (Figure 4k). Our findings of a reduced number of filled GCs in RAG1KO and CD1dKO mouse strains clearly points to a physiological role for NKT, but not NK, cells in maintaining conjunctival GCs.

\section{DISCUSSION}

Our findings indicate that innate NK and NKT cells are a major source of IL-13 in the conjunctival mucosa. IL-13 produced by these cells was found to have an essential role in homeostatic maintenance of conjunctival GCs. Furthermore, IL-13 also appeared to prevent the decrease in the number of filled conjunctival GCs in response to experimental DS. These findings demonstrate for the first time the dynamic interaction between IELs and maintenance of conjunctival GCs. Similar to other mucosal tissues, IL-13 was observed to promote GC differentiation in the conjunctiva.

Conjunctival NK and NKT cells were found to be high expressors of IL-13, with significantly greater IL13 mRNA transcripts in ocular NK+ than the NK + cells isolated from the spleen. The ocular surface environment may have unique features that promote higher IL-13 production by these cells.

Normal conjunctival mucosa has a higher number of PAS + GCs than other mucosal sites, such as lung and intestine. GC hyperplasia in these two tissues is often the result of inflammatory disease states, such as asthma, cystic fibrosis, chronic obstructive pulmonary disease, or helmintic infections. ${ }^{3-7}$ Th-2 immune inflammation, with increased production of IL-4, IL-13, and IL- 5 cytokines, is a common feature of all of these diseases. Mucus hypersecretion in asthma is a deleterious consequence that carries a high mortality risk. Both NK and NKT cells can be found in the lung, but neither makes up more than a few percentage of total leukocytes. ${ }^{47,48}$ Human studies indicate that NKT cells might not even be present at all. ${ }^{49}$ The literature to date on NKT cells and asthma is highly controversial, with studies reporting contradictory results. ${ }^{50-53}$ In contrast, NKT cells have been shown to be necessary for maximal expression of allergic conjunctivitis. ${ }^{54}$ Taken together, these findings indicate a homeostatic role for the resident ocular NK and NKT cells to maintain adequate population of GCs through production of IL-13 and maintenance of GCs. This is logical because excessive mucus production in the airway is bad, representing a disease state, whereas the ocular surface relies on GC secretions for maintaining tear stability, corneal protection, and a smooth optically clear cornea in normal circumstances. Therefore, constitutive expression of IL-13 cytokine may be required for homeostatic control of GCs and health of ocular surface.

IL-13 can have a profibrotic effect, and it has been implicated in airway remodeling and liver granuloma formation after Schistosoma infection. ${ }^{55} \mathrm{IL}-13$-mediated fibrosis results from increased extracellular matrix production by IL-13R-bearing fibroblasts. We found IL-13R $\alpha 1$ to be present primarily in the conjunctival epithelium, with sparse positive cells in the stroma of the normal conjunctiva. In pathological conditions where IL-13 has been implicated in stromal fibrosis, CD4 + T-cell infiltration has been noted. For example, IL-13 has been reported to have a role in ocular mucous membrane pemphigoid where it was found to stimulate collagen lattice contraction and migration of human conjunctival fibroblasts. ${ }^{56}$

After DS, we observed a decrease in the number of mucinfilled conjunctival GCs. Our results showed that exogenous administration of IL-13 prevented the decrease of GCs in response to DS. The concept that IL-13 is implicated in GC homeostasis is therefore not entirely surprising; however, the function of IL-13 on conjunctival GC maintenance has not been fully investigated. IL-13 has been extensively reported to promote GC hyperplasia in experimental models of asthma. One study showed that the airway epithelia of IL-4 and IL-13 transgenic mice demonstrated GC metaplasia and intratracheal instillations of IL-4- and IL-13-induced expression of the MUC5AC gene (the major secretory mucin produced by GCs) and GC metaplasia. ${ }^{57-59}$ Ocular GC hyperplasia has been noted in patients with atopic keratoconjunctivitis, another Th-2, allergic disease. ${ }^{60}$ Interestingly, the MRL/MpJ-Fas ${ }^{\mathrm{lpr}}$ mouse, which has been used as a model of Sjögren's syndrome, develops an increase in GC numbers and T-cell infiltration in the conjunctiva with aging. ${ }^{61}$ This mouse strain has been shown to be Th-2 biased. ${ }^{62,63}$

We observed a significant decrease in IL-13/IFN- $\gamma$ ratio in the conjunctiva after DS, which was accompanied by reduced number of filled GCs. The inverse holds true: an increased Th-2/Th-1 ratio was accompanied by GC hyperplasia in an experimental model of asthma. ${ }^{64}$ This interplay between IL-13 and IFN- $\gamma$ has been previously described. In lungs, exogenous administration of IFN- $\gamma$ was noted to antagonize the GC hyperplasia induced by IL-13. ${ }^{65}$ Adoptive transfer of T-helper 1 cells also suppressed GC hyperplasia in asthmatic mice. ${ }^{66}$ In cultured labial salivary gland biopsies obtained from patients with Sjögren's syndrome, a Th-1-biased disease, ${ }^{67}$ the concentration of IFN- $\gamma$, but not IL-13, was associated with greater lymphocytic infiltration. ${ }^{68}$ We have previously shown that dry eye elicits a mix of Th- 1 and Th-17 response, in humans and in our animal model. ${ }^{32,33}$ In the latter, we showed that IFN- $\gamma$ KO mice are resistant to DS-induced GC decrease; however, reconstitution of these mice with subconjunctival injections of IFN- $\gamma$ promoted conjunctival squamous metaplasia. ${ }^{32}$ Presenting immune data in the context of an IL-4/IFN- $\gamma$ ratio (or IL-13/IFN- $\gamma$ ratio) is an exceptionally powerful way of revealing the contribution of the immune response in immune-mediated diseases. This form of representation is powerful because much of immunity is indeed dichotomous: the outcome of the inflammation is based largely on the outcome of two competing arms of the immune system (often, Th- 1 and Th- 2 responses).

CsA is an immunosuppressant drug widely used systemically to increase survival of allogeneic organ transplants. It is also available as a topical emulsion to treat dry eye. CsA, which has been noted to increase the number of filled GCs in human dry eye, was also found to increase the number of NK/NKT and to increase GCs in the mouse conjunctiva. Our results show that it also increased IL-13 in NK + cells and decreased IFN- $\gamma$ 
and IL-17A mRNA in both NK+ and NK - populations. CsA has been show to inhibit the production of IFN- $\gamma$ and IL-17A in human patients with psoriasis, Vogt-Koyanagi-Harada syndrome, Bechet's disease, and rheumatoid arthritis. ${ }^{69-72}$ The beneficial effects of CsA on the GC numbers can be attributed to three different mechanisms that are concomitantly in place: first, preservation of NK/NKT + cells on the ocular surface; second, increased production of IL-13 by the NK/NKT + cell population; and third, decreasing the production of IFN $-\gamma$ by NK + and NK - cells. Collectively, CsA increases the IL-13/IFN- $\gamma$ ratio in the conjunctiva, therefore, preserving the homeostasis (IL-13) and preventing pathology (IFN- $\gamma$ ).

Loss or decrease in filled GCs is a universal feature of dry eye, and in severe ocular surface diseases, including Sjögren's syndrome, Stevens-Johnson syndrome, ocular mucous membrane pemphigoid, and graft-vs.-host disease, total GC loss may be observed. ${ }^{1,2}$ Retaining IL-13-producing NK cells in the conjunctiva may be a beneficial strategy in the treatment of ocular surface diseases associated with GC loss.

Our results demonstrate for the first time the dynamic interaction between innate resident NK/NKT cells and GCs in the conjunctival mucosa. This may be one reason why it has been so difficult to promote GC differentiation in vitro, because conjunctival epithelial cultures normally lack the environment provided by these IELs. Understanding the supportive and protective function of the resident IEL population may help us to design better treatment strategies to protect against GC loss in response to DS.

\section{METHODS}

Mice. This research protocol was approved by the Baylor College of Medicine Center for Comparative Medicine, and it conformed to the standards in the ARVO (Association for Research in Vision and Ophthalmology) Statement for the Use of Animals in Ophthalmic and Vision Research. C57BL/6 and Balb/c mice of both genders, 6-8 weeks old, were purchased from the Jackson Laboratory (Bar Harbor, ME). RAG1KO, STAT6KO, and CD1dKO mice were purchased from the Jackson Laboratory for establishing breeding colonies in our facility.

A breeder pair of IL-13KO (in C57BL/6 background) was kindly provided by Thomas A. Wynn (Laboratory of Parasitic Diseases, $\mathrm{NIH}$, Bethesda, MD) for establishing a breeding colony in our facility. All experiments were performed in C57BL/6 mice, unless otherwise noted.

Isolation of ocular surface murine cells. The eyes and lids of C57BL/6 mice were excised, pooled, and incubated in $10 \mathrm{ml}^{\text {of }} 5 \mathrm{mg} \mathrm{ml}^{-1}$ of Dispase II (Roche Molecular Biochemicals, Indianapolis, IN) in a shaker at $37^{\circ} \mathrm{C}$ for $1 \mathrm{~h}$, followed by neutralization with Hank's balanced salt solution (Invitrogen-Gibco, Grand Island, NY) supplemented with 3\% fetal bovine serum (Hyclone, Logan, UT). The mucosal side of the bulbar and tarsal conjunctivae and the peripheral cornea were then scraped with cytology brushes under a dissecting microscope to dislodge cells. Spleens from the same animals were surgically excised, smashed between two sterile frosted glass slides, and made into a single-cell suspension. Cell populations were individually collected, centrifuged at 2,000 r.p.m. for $5 \mathrm{~min}$, filtered, and resuspended. Cells collected by this technique were used either for cell separation using immunobeads or processed for flow cytometry. For each experiment, cells collected and pooled from 15 to 30 animals per group were used.
Cell enrichment using magnetic beads. $\gamma \delta+$ T cells from ocular surface tissues and spleens were isolated using a magnetic bead isolation (MACS system; Miltenyi Biotec, Auburn, CA), which utilizes a multiple step method consisting of initial depletion of B cells and CD11b + cells, followed by separation of $\gamma \delta$ T cells from $\alpha \beta+$ cells by positive selection of $\gamma \delta$ T cells, according to the manufacturer's instructions. The initial depletion of $\mathrm{B}$ cells and $\mathrm{CD} 11 \mathrm{~b}$ is achieved by a cocktail of magneticconjugated B220 (B-cell marker) and CD11b antibodies.

$\mathrm{NK}+$ and CD45 + cells from ocular surface tissues and spleens were isolated using a one-step procedure (NK by positive selection and CD45 by depletion, respectively), using magnetic microbeads directly conjugated to DX5 and CD45 monoclonal antibodies, respectively (MACS system; Miltenyi Biotec) according to the manufacturer's instructions. Positive and negative cell populations were used for flow cytometry, ELISPOT, or gene expression analysis.

Mouse IL-13 ELISPOT. Replicate $50 \mu \mathrm{l}$ cell suspensions containing $1.0 \times 10^{6}$ freshly isolated cells (as described above) were added to 96well polyvinylidene fluoride plates (Milipore, Billerica, MA), precoated with anti-mouse IL-13 capture antibody (R\&D Systems, Minneapolis, $\mathrm{MN}$ ). Wells containing either cells or positive control ( $3 \mathrm{ng}$ per well of recombinant mouse IL-13, R\&D Systems) or media alone (negative control) were incubated at $37^{\circ} \mathrm{C}$ with $5 \% \mathrm{CO}_{2}$ for $24 \mathrm{~h}$ in RPMI media (Invitrogen-Gibco). After washing, the plate was incubated overnight at $4{ }^{\circ} \mathrm{C}$, with biotinylated anti-mouse IL-13 detection antibody (R\&D Systems), followed by a 2 -h incubation with streptavidin-horseradish peroxidase (R\&D Systems) the next day. Red color development was achieved by incubating with NovaRed peroxidase substrate (Vector Labs, Burlingame, CA) for $15 \mathrm{~min}$. The polyvinylidene fluoride membrane was dried and the individual wells were punched out from the plate. The positive, red spots on the membrane were counted under a dissecting microscope (SMZ1500, Nikon, Melville, NY). Replicate wells were averaged from three individual experiments. The results are presented as number of spots.

MUC5AC enzyme-linked immunosorbent assay. Whole conjunctiva were surgically excised and lysed in RIPA lysis buffer containing $50 \mathrm{mM}$ Tris- $\mathrm{HCl}, 150 \mathrm{mM} \mathrm{NaCl}, 1 \% \mathrm{NP}-40,0.5 \%$ sodium deoxycholate, $2 \mathrm{mM}$ sodium fluoride, $2 \mathrm{mM}$ EDTA, $0.1 \%$ SDS, and a EDTA-free protease inhibitor cocktail tablet (Roche Applied Science, Indianapolis, IN). The cell extracts, pooled from two mice ( $n=3$ per condition), were sonicated and centrifuged at 14,000 r.p.m. and the supernatants were used for experiments. The total protein concentrations were measured by a Micro BCA protein assay kit (Pierce, Rockford, IL) using a microplate instrument (Tecan infinite M200; Tecan Systems, San Jose, CA) equipped with Magellan V6.55 software according to the manual instructions.

The MUC5AC concentration in whole conjunctiva samples was assayed with an enzyme-linked immunosorbent assay kit for Mouse Mucin 5 Subtype AC (Uscn Life Science, Wuhan, China), according to the manufacturer's protocol. Replicate $10 \mu \mathrm{l}$ per time point samples were added to 96-well plate precoated with anti-mouse MUC5AC polyclonal antibody. Wells containing supernatants, standards, or phosphate-buffered saline $+0.1 \%$ bovine serum albumin (BSA) alone (negative control) were incubated overnight at $4^{\circ} \mathrm{C}$. After washing, the plate was incubated with avidin-horseradish peroxidase for $1 \mathrm{~h}$ at $37^{\circ} \mathrm{C}$, followed by color development by adding 3,3',5, $5^{\prime}$-tetramethybezidine substrate. The enzyme-substrate reaction was terminated by the addition of a sulfuric acid solution and the color change was measured spectrophotometrically at a wavelength of $450 \mathrm{~nm}$. The concentration of MUC5AC in the samples was then determined by comparing the optical density of the samples with the standard curve using a microplate instrument (Tecan infinite M200) equipped with Magellan V6.55 software. Replicate wells were averaged and samples were normalized by total protein concentration. Results are presented as ng MUC5AC per ng total protein. 
Flow cytometry analysis of murine cells. Single-cell suspensions of cornea and conjunctiva, either before or after NK isolation, were stained with anti-CD16/32 (to block Fc receptors; BD Pharmingen, San Diego, $\mathrm{CA})$, followed by cell-surface staining with fluorescein isothiocyanateanti-pan NK (CD49b, clone DX5; BD Pharmingen), APC-anti-TCR $\alpha \beta$ (Abcam, Cambridge, MA), and phycoerythrin-anti NK1.1 (clone PK136; Biolegend, San Diego, CA). Positive controls consisted of splenocytes processed at the same time under the same protocol. Negative controls consisted of cells stained with fluorescein isothiocyanate, phycoerythrin, or APC-isotype antibodies (BD Pharmingen). Cells were resuspended in violet dye (live/dead cell fixable staining, Invitrogen-Molecular Probes, Carlsbad, CA) and washed. Cells were then resuspended in fixation-permeabilization solution (Cytofix/Cytoperm; BD Pharmingen) and stored at $4{ }^{\circ} \mathrm{C}$ until the next day when the analysis was performed. A BD LSRII Benchtop cytometer was used for flow cytometry and data were analyzed using BD Diva Software (BD Pharmingen).

Murine DS model. DS was induced by subcutaneous injection of scopolamine hydrobromide ( $0.5 \mathrm{mg}$ per $0.2 \mathrm{ml}$; Sigma-Aldrich, St Louis, MO), q.i.d. (0800, 1200, 1400, and 1700 hours), as previously described, for 5 or 10 consecutive days (DS5 or DS10, respectively) in C57BL/6 (DS5 and DS10), IL-13KO, STAT6KO, and CD1dKO mice (both DS5). ${ }^{27-29}$ Mice were placed in a cage with a perforated plastic screen on one side to allow airflow from a fan placed 6 inches in front of it for $16 \mathrm{~h}$ per day. Room humidity was maintained at 30-35\%. Control mice were maintained in a nonstressed environment containing 50-75\% relative humidity without exposure to forced air.

Exogenous administration of CsA. CsA has been shown to increase conjunctival GC density in humans and mice. ${ }^{34-36}$ To evaluate the effects of CsA in the NK population, DS was induced in three groups of C57BL/ 6 mice: DS5 control group received no topical therapy, a second group received $1 \mu \mathrm{l}$ of $0.05 \%$ cyclosporine ophthalmic emulsion q.i.d. (DS5 + CsA), and a third group received $1 \mu \mathrm{l}$ of CsA vehicle (polysorbate $801 \%$, glycerin $1 \%$, and castor oil) b.i.d. for 5 days. All mice were killed at DS5. Each experimental group/time point consisted of 55 different animals divided in 6 independent experiments.

Exogenous administration of IL-13. To evaluate if IL-13 could rescue DS-induced GC loss, C57BL/6 mice were divided into three treatment groups: (i) DS5 control subjects, which received no ocular injections; (ii) vehicle control animals, which received bilateral subconjunctival injections $(20 \mu \mathrm{l}$ per eye) of $0.1 \%$ BSA in phosphate-buffered saline (DS5 + BSA); (iii) DS5 + IL-13 mice, which received daily bilateral subconjunctival injections of recombinant murine IL-13 (20 ng per eye per injection, dissolved in $20 \mu \mathrm{l}$ of $0.1 \%$ BSA in phosphate-buffered saline (R\&D Systems) for 4 days. Additional control groups included nonstressed mice (no injections, no dry eye) and nonstressed mice that received bilateral injections of IL-13 or BSA (nonstressed + BSA or nonstressed + IL-13), as described. All mice were killed at DS5. Each experimental group/strain consisted of three different animals.

In vivo depletion of $\mathrm{NK}^{+}$cells. In vivo depletion of $\mathrm{NK}^{+}$cells was performed weekly by intraperitoneal injection of $100 \mathrm{ng}$ of mouse anti-NK antibody (NK1.1, clone PK136, Biolegend) ${ }^{42-46}$ to nonstressed C57BL/6 mice or CD1dKO, from 3 to 8 weeks of age. A separate group of C57BL/6 mice that received anti-NK treatment was also subjected to DS for 5 days at the age of 8 weeks. Controls consisted of litter mates that received isotype control antibody injection (mouse IgG; Sigma-Aldrich) for the same duration. Each experimental group/strain consisted of three different animals.

RNA isolation and real-time PCR. Total RNA, enriched for mRNA, was isolated from cells remaining after separation with immunobeads, lysed by a guanidine-isothiocyanate-containing lysis buffer, followed by selective binding of RNA to the RNeasy MinElute (Qiagen, Valencia, CA) silica-gel-based membrane. Total RNA from the cornea and conjunctiva collected and pooled from nonstressed, DS5, and DS10 (one sample consisted of four pooled mice per time point for each experiment, in four experiments) was extracted using an acid guanidium thiocyanate-phenol-chloroform method as previously described. ${ }^{28}$ Samples were treated with DNAse to prevent genomic DNA contamination according to the manufacturer's instructions (Qiagen).

The RNA concentration was measured by its absorption at $260 \mathrm{~nm}$ and samples were stored at $-80^{\circ} \mathrm{C}$ until use. First-strand complementary DNA was synthesized with random hexamers by M-MuLV reverse transcription (Ready-To-Go You-Prime First-Strand Beads; GE Healthcare, Arlington Heights, NJ), as previously described. ${ }^{28}$ Realtime PCR was performed with specific MGB probes (Taqman; Applied Biosystems (ABI), Foster City, CA) and PCR master mix (Taqman Gene Expression Master Mix), in a commercial thermocycling system (Mx3005P QPCR System; Stratagene, La Jolla, CA), according to the manufacturer's recommendations. Murine MGB probes were glyceraldehyde-3-phosphate dehydrogenase (GAPDH; Mm99999915_ m1), IL-17A (Mm00439619_m1), IFN- $\gamma$ (Mm00801778_m1), IL-13 (Mm00434165_m1), CD49b (Mm00434371_m1), IL-4 (Mm00445259_ m1), IL-17F (Mm00517640_m1), IL-21 (Mm00444241_m1), IL-22 (Mm00521423_m1), and MUC5AC (Mm01276720_m1). The GAPDH gene was used as an endogenous reference for each reaction. The results of quantitative PCR were analyzed by the comparative $\mathrm{C}_{\mathrm{T}}$ method where target change $=2^{-\Delta \Delta C T}$. The results were normalized by the $C_{T}$ value of GAPDH. In the DS model, the mean $\mathrm{C}_{\mathrm{T}}$ of relative mRNA level in the nonstressed control group was used as the calibrator. In the cell separation experiments, the mean $\mathrm{C}_{\mathrm{T}}$ of relative mRNA level in $\mathrm{NK}+$ cell population from spleen was used as the calibrator.

Histology and PAS staining. GC density was evaluated in C57BL/6 with and without DS $(n=8), \mathrm{C} 57 \mathrm{BL} / 6$ after receiving subconjunctival injections of IL-13 $(n=3)$ or vehicle control $(n=3)$, C57BL/ 6 with topical treatment with CsA or its vehicle ( $n=3$ for each), C57BL/ 6 or CD1dKO that received in vivo depletion with $\mathrm{NK}$ antibody $(n=6$, and $n=3$, respectively) or treatment with isotype control ( $n=6$, and $n=3$, respectively), STAT6KO $(n=5), \mathrm{Balb} / \mathrm{c}(n=5), \mathrm{IL}-13 \mathrm{KO}(n=5), \mathrm{RAG1KO}(n=5)$, and CD1dKO mice $(n=8)$.

Lungs, small intestine, eyes, and ocular adnexa were surgically excised, fixed in $10 \%$ formalin, paraffin embedded, and $8 \mu \mathrm{m}$ sections were cut. Ocular sections were cut at the center of the eye, where the lens has its maximum diameter. Sections were stained with PAS reagent for measuring GC density and were examined and photographed with a microscope equipped with a digital camera (Eclipse E400 with a DS-Fil; Nikon, Mclville, NY). The number of GCs in the superior and inferior conjunctiva was measured in three sections from each eye that were $300 \mu \mathrm{m}$ apart from each other, using image-analysis software (NIS Elements Software, version 3.0, BR, Nikon) and expressed as the number of GCs per $\mathrm{mm}$.

Immunohistochemistry. Immunohistochemistry was performed to detect IL-13 and IL-13R $\alpha 1$ in the cornea and conjunctival epithelium of nonstressed C57BL/6 mice.

The eyes and adnexa of mice $(n=5)$ were excised, embedded in optimal cutting temperature (OCT compound; VWR, Suwanee, GA), and flash frozen in liquid nitrogen. Sagittal 8 - $\mu \mathrm{m}$ sections were cut with a cryostat (HM 500; Micron, Waldorf, Germany) and placed on glass slides that were stored at $-80^{\circ} \mathrm{C}$.

Cryosections were stained with primary rabbit anti-IL-13 (ABD Serotec, Raleigh, NC) and IL-13R $\alpha 1$ antibodies (Santa Cruz, Santa Cruz, CA) and goat anti-rabbit biotinylated secondary antibody (BD Pharmingen) and a Vectastain Elite ABC kit using NovaRed reagents (Vector) as previously described. ${ }^{28}$ Secondary antibody alone and appropriate isotype (BD Biosciences) controls were also performed. Three sections from each animal were examined and photographed with a microscope equipped with a digital camera (Eclipse E400 with a DS-Fi1; Nikon). 
Statistical analysis. The normality of data was checked with the Kolmogorov-Smirnov test using the Dallal and Wilkinson approximation. Kruskall-Wallis test (multiple comparison test) was used to determine overall statistical significance followed by a two-tailed $t$-test for individual differences in treatment groups, using $P \leqslant 0.05$ as statistically significant. Two-way analysis of variance with Bonferoni post hoc testing was used for statistical comparisons of gene expression profiles in NK-positive and NK-negative cell populations. These tests were performed using GraphPad Prism 5.0 software (GraphPad Software, San Diego, CA).

SUPPLEMENTARY MATERIAL is linked to the online version of the paper at http://www.nature.com/mi

\section{ACKNOWLEDGMENTS}

Support: This study was supported by the NIH grant EY018888 (to C.S.D.P.), EY11915 (to S.C.P.), Research to Prevent Blindness, the Oshman Foundation, William Stamps Farish Fund, and the Hamill Foundation.

\section{DISCLOSURE}

The authors declared no conflict of interest.

(C) 2011 Society for Mucosal Immunology

\section{REFERENCES}

1. Nakamura, T., Nishida, K., Dota, A., Matsuki, M., Yamanishi, K. \& Kinoshita, S. Elevated expression of transglutaminase 1 and keratinization-related proteins in conjunctiva in severe ocular surface disease. Invest. Ophthalmol. Vis. Sci. 42, 549-556 (2001).

2. Pflugfelder, S.C., Tseng, S.C.G., Yoshino, K., Monroy, D., Felix, C. \& Reis, B.L. Correlation of goblet cell density and mucosal epithelial membrane mucin expression with rose bengal staining in patients with ocular irritation. Ophthalmology 104, 223-235 (1997).

3. Shahzeidi, S., Aujla, P.K., Nickola, T.J., Chen, Y., Alimam, M.Z. \& Rose, M.C. Temporal analysis of goblet cells and mucin gene expression in murine models of allergic asthma. Exp. Lung Res. 29, 549-565 (2003).

4. Shim, J.J. et al. IL-13 induces mucin production by stimulating epidermal growth factor receptors and by activating neutrophils. Am. J. Physiol. Lung Cell Mol. Physiol. 280, L134-L140 (2001).

5. Kondo, M. et al. Elimination of IL-13 reverses established goblet cell metaplasia into ciliated epithelia in airway epithelial cell culture. Allergol. Int. 55, 329-336 (2006).

6. McDermott, J.R., Humphreys, N.E., Forman, S.P., Donaldson, D.D. \& Grencis, R.K. Intraepithelial NK cell-derived IL-13 induces intestinal pathology associated with nematode infection. J. Immunol. 175, 3207-3213 (2005).

7. Evans, C.M. \& Koo, J.S. Airway mucus: the good, the bad, the sticky. Pharmacol. Ther. 121, 332-348 (2009).

8. Knop, N. \& Knop, E. Conjunctiva-associated lymphoid tissue in the human eye. Invest. Ophthalmol. Vis. Sci. 41, 1270-1279 (2000).

9. Dua, H.S. et al. Mucosa specific lymphocytes in the human conjunctiva, corneoscleral limbus and lacrimal gland. Curr. Eye Res. 13, 87-93 (1994).

10. Dua, H.S., Gomes, J.A., Donoso, L.A. \& Laibson, P.R. The ocular surface as part of the mucosal immune system: conjunctival mucosa-specific lymphocytes in ocular surface pathology. Eye (Lond). 9 (Pt 3), 261-267 (1995).

11. Bienenstock, J. \& Befus, D. Gut- and bronchus-associated lymphoid tissue. Am. J. Anat. 170, 437-445 (1984).

12. Wotherspoon, A.C., Hardman-Lea, S. \& Isaacson, P.G. Mucosaassociated lymphoid tissue (MALT) in the human conjunctiva. J. Pathol. 174, 33-37 (1994).

13. Chan, J.H., Amankwah, R., Robins, R.A., Gray, T. \& Dua, H.S. Kinetics of immune cell migration at the human ocular surface. Br. J. Ophthalmol. 92, 970-975 (2008).

14. Fuss, I.J. \& Strober, W. The role of IL-13 and NK T cells in experimental and human ulcerative colitis. Mucosal. Immunol. 1 (Suppl 1), S31-S33 (2008).

15. Middendorp, S. \& Nieuwenhuis, E.E. NKT cells in mucosal immunity. Mucosal Immunol. 2, 393-402 (2009).

16. Matangkasombut, P., Pichavant, M., Dekruyff, R.H. \& Umetsu, D.T. Natural killer T cells and the regulation of asthma. Mucosal Immunol. 2, 383-392 (2009).
17. Balato, A., Unutmaz, D. \& Gaspari, A.A. Natural killer T cells: an unconventional T-cell subset with diverse effector and regulatory functions. J. Invest. Dermatol. 129, 1628-1642 (2009).

18. Kondo, M., Tamaoki, J., Takeyama, K., Nakata, J. \& Nagai, A. Interleukin13 induces goblet cell differentiation in primary cell culture from Guinea pig tracheal epithelium. Am. J. Respir. Cell Mol. Biol. 27, 536-541 (2002).

19. Laoukili, J. et al. IL-13 alters mucociliary differentiation and ciliary beating of human respiratory epithelial cells. J. Clin. Invest. 108, 1817-1824 (2001).

20. Walzer, T. et al. Identification, activation, and selective in vivo ablation of mouse NK cells via NKp46. Proc. Natl. Acad. Sci. USA 104, 3384-3389 (2007).

21. Liu, Q. et al. IL-18 stimulates IL-13-mediated IFN-gamma-sensitive host resistance in vivo. Eur. J. Immunol. 36, 1187-1198 (2006).

22. Chen, H. \& Paul, W.E. Cultured NK1.1+ CD4+ T cells produce large amounts of IL-4 and IFN-gamma upon activation by anti-CD3 or CD1. J. Immunol. 159, 2240-2249 (1997).

23. Beagley, K.W. et al. Differences in intraepithelial lymphocyte T cell subsets isolated from murine small versus large intestine. J. Immunol. 154, 5611-5619 (1995).

24. Naiki, Y., Nishimura, H., Itohara, S. \& Yoshikai, Y. gammadelta T cells may dichotomously modulate infection with avirulent Salmonella choleraesuis via IFN-gamma and IL-13 in mice. Cell Immunol. 202, 61-69 (2000).

25. Park, S.W. et al. Interleukin-13 and its receptors in idiopathic interstitial pneumonia: clinical implications for lung function. J. Korean Med. Sci. 24, 614-620 (2009).

26. Arase, H., Saito, T., Phillips, J.H. \& Lanier, L.L. Cutting edge: the mouse NK cell-associated antigen recognized by DX5 monoclonal antibody is CD49b (alpha 2 integrin, very late antigen-2). J. Immunol. 167, 1141-1144 (2001).

27. Niederkorn, J.Y. et al. Desiccating stress induces T cell-mediated Sjogren's syndrome-like lacrimal keratoconjunctivitis. J. Immunol. 176, 3950-3957 (2006).

28. de Paiva, C.S. et al. Apical corneal barrier disruption in experimental murine dry eye is abrogated by methylprednisolone and doxycycline. Invest. Ophthalmol. Vis. Sci. 47, 2847-2856 (2006).

29. de Paiva, C.S. et al. Corticosteroid and doxycycline suppress MMP-9 and inflammatory cytokine expression, MAPK activation in the corneal epithelium in experimental dry eye. Exp. Eye Res. 83, 526-535 (2006).

30. Luo, L., Li, D.Q., Doshi, A., Farley, W., Corrales, R.M. \& Pflugfelder, S.C. Experimental dry eye stimulates production of inflammatory cytokines and MMP-9 and activates MAPK signaling pathways on the ocular surface. Invest. Ophthalmol. Vis. Sci. 45, 4293-4301 (2004).

31. Pitcher, J.I. et al. Pharmacological cholinergic blockade stimulates inflammatory cytokine production in the mouse lacrimal gland. Invest. Ophthalmol. Vis. Sci. (in press) (2010).

32. de Paiva, C.S. et al. Dry eye-induced conjunctival epithelial squamous metaplasia is modulated by interferon-\{gamma\}. Invest. Ophthalmol. Vis. Sci. 48, 2553-2560 (2007).

33. de Paiva, C.S. et al. IL-17 disrupts corneal barrier following desiccating stress. Mucosal Immunol. 2, 243-253 (2009).

34. Sall, K., Stevenson, O.D., Mundorf, T.K. \& Reis, B.L. Two multicenter, randomized studies of the efficacy and safety of cyclosporine ophthalmic emulsion in moderate to severe dry eye disease. CsA Phase 3 Study Group. Ophthalmology 107, 631-639 (2000).

35. Strong, B., Farley, W., Stern, M.E. \& Pflugfelder, S.C. Topical cyclosporine inhibits conjunctival epithelial apoptosis in experimental murine keratoconjunctivitis sicca. Cornea 24, 80-85 (2005).

36. Pangelinan, S.B. et al. Topical cyclosporine emulsion modulates immune response in experimental dry eye [abstr]. Invest. Ophthalmol. Vis. Sci. 49, 440 (2008).

37. Jiang, H., Harris, M.B. \& Rothman, P. IL-4/IL-13 signaling beyond JAK/ STAT. J. Allergy Clin. Immunol. 105, 1063-1070 (2000).

38. Kaplan, M.H., Schindler, U., Smiley, S.T. \& Grusby, M.J. Stat6 is required for mediating responses to IL-4 and for development of Th2 cells. Immunity 4, 313-319 (1996).

39. Kuperman, D., Schofield, B., Wills-Karp, M. \& Grusby, M.J. Signal transducer and activator of transcription factor 6 (Stat6)-deficient mice are protected from antigen-induced airway hyperresponsiveness and mucus production. J. Exp. Med. 187, 939-948 (1998).

40. Akimoto, T. et al. Abrogation of bronchial eosinophilic inflammation and airway hyperreactivity in signal transducers and activators of transcription (STAT)6-deficient mice. J. Exp. Med. 187, 1537-1542 (1998). 
41. Corrales, R.M., Stern, M.E., de Paiva, C.S., Welch, J., Li, D.Q. \& Pflugfelder, S.C. Desiccating stress stimulates expression of matrix metalloproteinases by the corneal epithelium. Invest. Ophthalmol. Vis. Sci. 47, 3293-3302 (2006)

42. Muhlen, K.A. et al. NK cells, but not NKT cells, are involved in Pseudomonas aeruginosa exotoxin A-induced hepatotoxicity in mice. J. Immunol. 172, 3034-3041 (2004).

43. Hazlett, L.D., Li, Q., Liu, J., McClellan, S., Du, W. \& Barrett, R.P. NKT cells are critical to initiate an inflammatory response after Pseudomonas aeruginosa ocular infection in susceptible mice. J. Immunol. 179, 1138-1146 (2007)

44. Sentman, C.L., Kumar, V., Koo, G. \& Bennett, M. Effector cell expression of NK1.1, a murine natural killer cell-specific molecule, and ability of mice to reject bone marrow allografts. J. Immunol. 142, 1847-1853 (1989)

45. Andoniou, C.E. et al. Interaction between conventional dendritic cells and natural killer cells is integral to the activation of effective antiviral immunity. Nat. Immunol. 6, 1011-1019 (2005).

46. Koo, G.C., Dumont, F.J., Tutt, M., Hackett, J. Jr. \& Kumar, V. The NK1.1(-) mouse: a model to study differentiation of murine NK cells. J. Immunol. 137, 3742-3747 (1986)

47. Mutalithas, K. et al. Bronchoalveolar lavage invariant natural killer T cells are not increased in asthma. J. Allergy Clin. Immunol. 119, 1274-1276 (2007).

48. Rock, M., Yoder, S., Hoskins, A., Ajayi, W.U., Sheller, J.R. \& Dworski, R. Effect of allergen challenge on the percentage of natural killer T cells in patients with atopic asthma. Ann. Allergy Asthma Immunol. 102, 432-437 (2009).

49. Vijayanand, P. et al. Invariant natural killer T cells in asthma and chronic obstructive pulmonary disease. N. Engl. J. Med. 356, 1410-1422 (2007).

50. Brown, D.R. et al. Beta 2-microglobulin-dependent NK1.1+ T cells are not essential for T helper cell 2 immune responses. J. Exp. Med. 184, 1295-1304 (1996)

51. Zhang, Y., Rogers, K.H. \& Lewis, D.B. Beta 2-microglobulin-dependent T cells are dispensable for allergen-induced $T$ helper 2 responses. J. Exp. Med. 184, 1507-1512 (1996).

52. Korsgren, M. et al. Natural killer cells determine development of allergeninduced eosinophilic airway inflammation in mice. J. Exp. Med. 189 553-562 (1999)

53. Das, J. et al. Natural killer T cells and CD8+ T cells are dispensable for $T$ cell-dependent allergic airway inflammation. Nat. Med. 12, 1345-1346 (2006).

54. Reyes, N.J., Mayhew, E., Chen, P.W. \& Niederkorn, J.Y. NKT cells are necessary for maximal expression of allergic conjunctivitis1. Int. Immunol. 22, 627-636 (2010).

55. Kaviratne, M. et al. IL-13 activates a mechanism of tissue fibrosis that is completely TGF-beta independent. J. Immunol. 173, 4020-4029 (2004).

56. Saw, V.P. et al. Conjunctival interleukin-13 expression in mucous membrane pemphigoid and functional effects of interleukin-13 on conjunctival fibroblasts in vitro. Am. J. Pathol. 175, 2406-2415 (2009).
57. Cohn, L., Homer, R.J., Marinov, A., Rankin, J. \& Bottomly, K. Induction of airway mucus production by Thelper 2 (Th2) cells: a critical role for interleukin 4 in cell recruitment but not mucus production. J. Exp. Med. 186, 1737-1747 (1997).

58. Temann, U.A. et al. A novel role for murine IL-4 in vivo: induction of MUC5AC gene expression and mucin hypersecretion. Am. J. Respir. Cell Mol. Biol. 16, 471-478 (1997).

59. Zhu, Z. et al. Pulmonary expression of interleukin-13 causes inflammation, mucus hypersecretion, subepithelial fibrosis, physiologic abnormalities, and eotaxin production. J. Clin. Invest. 103, 779-788 (1999).

60. Roat, M.I., Ohji, M., Hunt, L.E. \& Thoft, R.A. Conjunctival epithelial cell hypermitosis and goblet cell hyperplasia in atopic keratoconjunctivitis. Am. J. Ophthalmol. 116, 456-463 (1993).

61. Diebold, Y., Chen, L.L., Tepavcevic, V., Ferdman, D., Hodges, R.R. \& Dartt, D.A. Lymphocytic infiltration and goblet cell marker alteration in the conjunctiva of the MRL/MpJ-Fas(lpr) mouse model of Sjogren's syndrome. Exp. Eye Res. 84, 500-512 (2007).

62. Jabs, D.A. et al. Autoimmune Th2-mediated dacryoadenitis in MRL/MpJ mice becomes Th1-mediated in IL-4 deficient MRL/MpJ mice. Invest Ophthalmol. Vis. Sci. 48, 5624-5629 (2007).

63. Jabs, D.A., Lee, B., Whittum-Hudson, J.A. \& Prendergast, R.A. Th1 versus Th2 immune responses in autoimmune lacrimal gland disease in MRL/Mp mice. Invest. Ophthalmol. Vis. Sci. 41, 826-831 (2000).

64. Porter, P. et al. Link between allergic asthma and airway mucosal infection suggested by proteinase-secreting household fungi. Mucosal Immunol. 2 , 504-517 (2009).

65. Ford, J.G. et al. II-13 and IFN-gamma: interactions in lung inflammation. J. Immunol. 167, 1769-1777 (2001).

66. Irifune, K. et al. Adoptive transfer of T-helper cell type 1 clones attenuates an asthmatic phenotype in mice. Eur. Respir. J. 25, 653-659 (2005).

67. Brookes, S.M. et al. T cell clones from a Sjogren's syndrome salivary gland biopsy produce high levels of IL-10. Clin. Exp. Immunol. 103, 268-272 (1996).

68. Mitsias, D.I. et al. The Th1/Th2 cytokine balance changes with the progress of the immunopathological lesion of Sjogren's syndrome. Clin. Exp. Immunol. 128, 562-568 (2002).

69. Haider, A.S. et al. Identification of cellular pathways of "type 1," Th17T cells, and TNF- and inducible nitric oxide synthase-producing dendritic cells in autoimmune inflammation through pharmacogenomic study of cyclosporine A in psoriasis. J. Immunol. 180, 1913-1920 (2008).

70. Liu, X. et al. Inhibitory effect of Cyclosporin A and corticosteroids on the production of IFN-gamma and IL-17 by T cells in Vogt-Koyanagi-Harada syndrome. Clin. Immunol. 131, 333-342 (2009).

71. Zhang, C., Zhang, J., Yang, B. \& Wu, C. Cyclosporin A inhibits the production of IL-17 by memory Th17 cells from healthy individuals and patients with rheumatoid arthritis. Cytokine 42, 345-352 (2008).

72. Chi, W. et al. Production of interleukin-17 in Behcet's disease is inhibited by cyclosporin A. Mol. Vis. 16, 880-886 (2010). 